\title{
DESCRIÇÃO DA FÊMEA DE ARGYROTHEMIS ARGENTEA (ODONATA, LIBELLULIDAE)
}

\author{
Janira M. Costa ${ }^{1,3}$ \\ Barbara B. Oldrini',
}

\begin{abstract}
DESCRIPTION OF THE FEMALE OF ARGYROTHEMIS ARGENTEA (ODONATA, LIBELLULIDAE). The female of Argyrothemis argentea Ris, 1911 is described and illustrated for the first time. New records expand the distribution range of the species to Central West Region of Brazil.

KEYWORDS. Argyrothemis, Brachydiplacinae, Odonata, taxonomy, Neotropical.

\section{INTRODUÇÃO}

Ris (1911) propôs o gênero Argyrothemis, monotípico, para espécie-tipo A. argentea, com base em um macho de Caiena, Guiana Francesa. O gênero difere dos outros de Libellulidae brasileiros, incluídos na subfamília Brachydiplacinae, por apresentar a alça anal indistinta e a membrânula pequena, quase ausente. Até o momento, A. argentea é registrada para o Brasil, Venezuela e Guiana Francesa.

$\mathrm{O}$ exame do material do Brasil, procedente da região Norte (Amazonas, Pará e Rondônia), região Centro-Oeste (Mato Grosso) e da Guiana Francesa, permitiu identificar as fêmeas de Belém (Pará), Manaus (Amazonas) e Sinop (Mato Grosso).

O objetivo é descrever a fêmea de Argyrothemis argentea Ris, 1911, permitindo definir, com segurança, uma maior afinidade do gênero Argyrothemis com Uracis Rambur, 1842 e ampliar a área de distribuição da espécie.
\end{abstract}

\section{MATERIAL E MÉTODOS}

Foram examinados 22 ơ e 4 procedentes de diferentes localidades do Brasil e de Caiena, Guiana Francesa. O material encontra-se depositado na coleção do Museu Nacional, Universidade Federal do Rio de Janeiro (MNRJ) e na coleção Angelo Barbosa M. Machado, Universidade Federal de Minas Gerais (ABMM). Para o estudo morfológico, os apêndices anais e pênis foram tratados com solução de $\mathrm{KOH}$ a $10 \%$ e corados com azul de metileno. Os apêndices anais de um exemplar do Mato Grosso foram tratados com hipoclorito de sódio para obter melhor visualização dos dentes dos apêndices superiores do macho. As fotografias foram obtidas com máquina digital e trabalhadas em programa Adobe Photoshop.

1. Museu Nacional, Universidade Federal do Rio de Janeiro, Quinta da Boa Vista, São Cristóvão, 20940-040, Rio de Janeiro, RJ, Brasil.

2. Estagiária MNRJ.

3. Bolsista CNPq. 

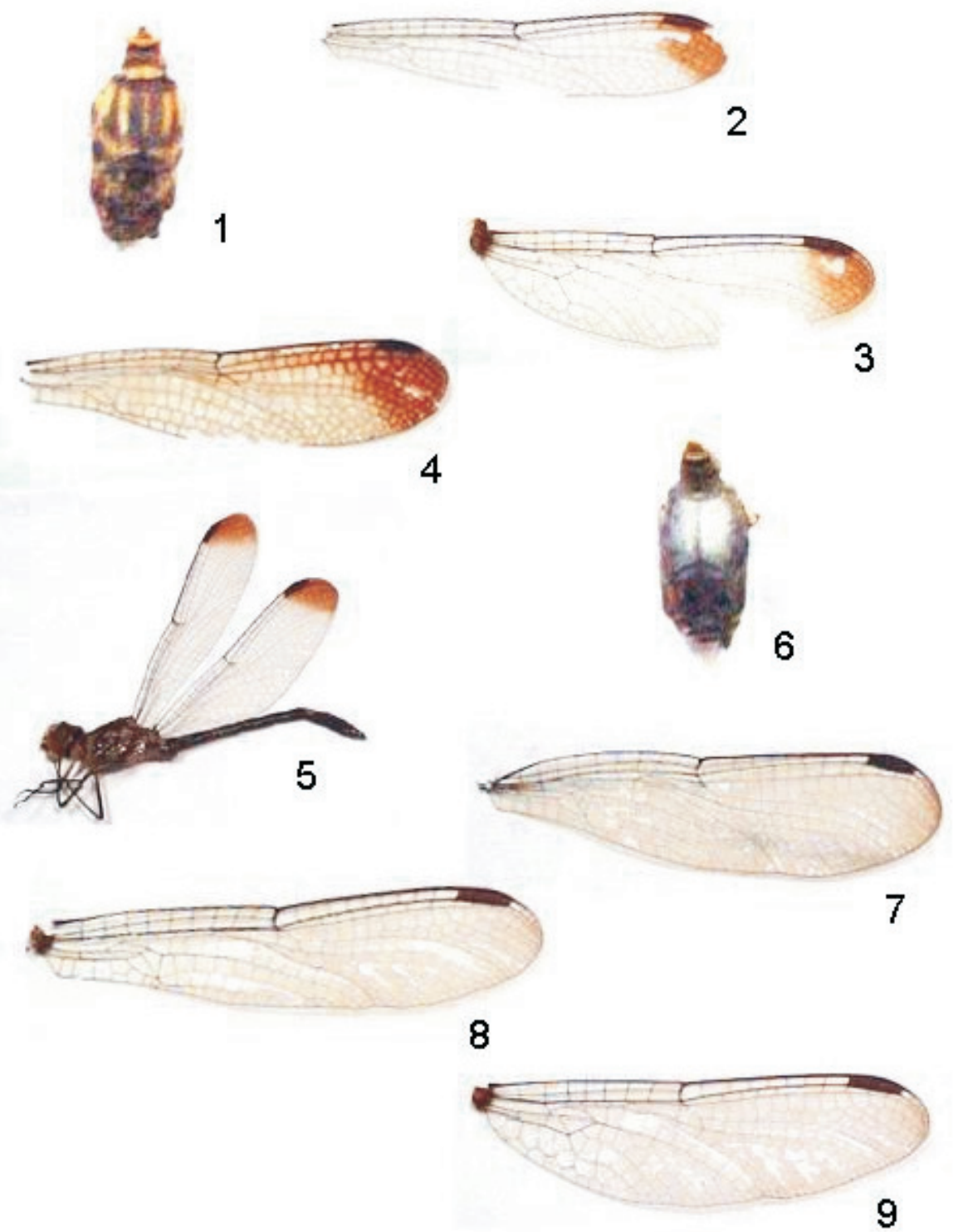

Figs. 1-9. Argyrothemis argentea Ris, 1911. Fêmea: 1, pterotórax, vista dorsal, $7 \mathrm{~mm}$; 2, asa anterior (Mato Grosso, Sinop), $23 \mathrm{~mm}$; 3, asa posterior (Mato Grosso, Sinop), $22 \mathrm{~mm}$; 4, asa anterior (Amazonas, Manaus), $24 \mathrm{~mm}$. Macho: 5, (Amazonas, Manaus), $32 \mathrm{~mm}$; 6, pterotórax, dorsal, $7 \mathrm{~mm}$; asa anterior: 7, (Mato Grosso, Sinop), $22 \mathrm{~mm}$; 8, (Amazonas, Manaus), $25 \mathrm{~mm}$; 9, asa posterior (Mato Grosso, Sinop), $21 \mathrm{~mm}$. 


\section{Argyrothemis argentea Ris, 1911}

(Figs. 1-20)

Argyrothemis argentea Ris, 1911:389, figs. 236-238 (holótipo O’' Institut Royal des Sciences Naturelles (IRSN), não examinado, localidade tipo: Caiena, Guiana Francesa); RIs, 1916:1130; BRIDGES, $1994: 18$ (cat.); Steinmann, 1997:339 (cat.).

Diagnose. A fêmea de Argyrothemis argentea é similar a de Uracis Rambur, 1842 (RAMBUR, 1842, pr. 2, fig. 5e) pela forma e tamanho do ovipositor (fig. 4), porém difere pela ausência de alça anal na asa posterior (fig. 14).

Fêmea (Mato Grosso, Sinop). Cabeça (fig. 10) pequena (2,5mm); sutura ocular ampla; fronte proeminente, arredondada; sulco frontal raso. Tórax com lobo posterior do protórax grande $(3,8 \mathrm{~mm})$, ereto, ornado com pêlos longos, esbranquiçados; sulco mediano, em vista dorsal, profundo e estreito. Pterotórax (figs. 1, 11, 12) ligeiramente mais largo que o dos machos; pernas longas e delgadas; espinhos tibiais numerosos, finos e longos, fortemente divergentes; unhas tarsais delgadas. Asas (figs. 2-4) longas, maiores que o comprimento do abdômen; as anteriores com 9 antenodais e 7 pós-nodais e as posteriores com 7 antenodais e 7 pós-nodais; pterostigma ocupando 3 células; triângulos livres, com lado costal quebrado, semelhante ao do macho. Última antenodal incompleta; uma nervura cúbito-anal na asa anterior e duas na posterior. Setor radial suplementar pouco evidenciado; campo discoidal com lados paralelos e única fileira de células, passando a duas fileiras na altura da última antenodal e terminando na borda da asa com 4 células; alça anal ausente ou ligeiramente vestigial. Abdômen fino, cilíndrico. Apêndices superiores (fig. 13) cilíndricos e alongados, ultrapassando as placas genitais; projeção do nono segmento, em vista lateral, cilíndrica, ligeiramente curvada. Ovipositor alongado, ultrapassando a extremidade distal do décimo segmento.

Coloração. Mancha na metade basal da fronte e base do vértex azul-metálicas; clípeo, pós-clípeo, labro e lábio amarelo-pálidos. Face posterior da cabeça negra. Dorso do pterotórax (fig. 1) e espaço interalar castanhos, com faixas longitudinais, pálidas; sutura umeral com faixa estreita enegrecida; meso e meta-epímero com faixas escuras incompletas; meso e meta-episterno castanhos; pernas com a base dos fêmures amarela; tíbias e tarsos enegrecidos. Asas hialinas, com extremidade distal castanha, iniciando na base da quinta (fig. 4) ou da última pós-nodal (figs. 2, 3); pterostigma negro. Abdômen negro, com máculas amarelas: uma dorso-lateral na metade anterior do segundo segmento, uma lateral alongada nos segmentos 3 a 5 e uma basal, não interrompida pela carena dorsal, no segmento 7 .

Variação. No exemplar do Mato Grosso, a coloração da metade basal da fronte e base do vértex reduz-se a uma pequena mancha; no do Pará e em um do Mato Grosso, a face posterior da cabeça possui duas máculas pálidas dispostas lateralmente; em um exemplar do Mato Grosso e um do Amazonas, o abdômen possui mácula amarela nos segmentos 3 a 7 .

Dimensões, em mm. Comprimento total, 31 a 32; comprimento das asas anteriores, 23 a 24; comprimento das asas posteriores, 22 a 23; comprimento do pterostigma, 2,5 a 3; comprimento do abdômen, 20 a 22.

Macho (Mato Grosso, Sinop) (figs. 5-9, 14-20). Além dos caracteres citados por Ris (1911), outros são aqui apresentados para o reconhecimento da espécie: 1) asas hialinas, com mancha castanho-clara na extremidade distal (figs. 5, 7-9); 2) sexto segmento do abdômen com mácula amarela; 3) apêndices superiores com 1 a 4 dentes e 4) pênis com o segmento distal reto (figs. 15,16 ).

Dimensões, em mm (média e desvio padrão; número de indivíduos; intervalo de classe, entre parênteses). Comprimento total: $28 \pm 4,33, \mathrm{n}=22$ (26-30); comprimento da asa anterior, 23,5 $\pm 5,74, \mathrm{n}=22(22-25)$; comprimento da asa posterior, $22 \pm 3,20, \mathrm{n}=22(20$ - 
24); comprimento do pterostigma, $2,75 \pm 12,72, \mathrm{n}=22$ (25-30); comprimento do abdômen, $18,66 \pm 7,57, \mathrm{n}=22(17-20)$.

Material examinado. GUIANA FRANCESA, Rout 05 ph 8, ơ , 27.X.1990, Gallard col. (MNRJ). BRASIL, Amazonas: $\sigma^{7}$, s/ dados (ABMM); Manaus, $\sigma^{7}, 24 . V .1986$, A. Machado col. (ABMM); $\sigma^{7}$, X.1959, N. D. Santos col. (MNRJ); (Igarapé do Acampamento Porto Alegre), 20', 14.VII.1986; O', 15.I.1986, L. F. Netto col. (MNRJ); (Igarapé Acampamento Florestal), \&, 16.XI.1985, L. F. Netto col. (MNRJ); 20', 17.XII.1985, L. F. Netto col. (MNRJ); ○’,, , 20.XII.1985, L. F. Netto col. (MNRJ); (Igarapé cidade de Powell), ơ, 28.XII.1985 (MNRJ); Rondônia: Porto Velho, ơ, 3.V.1922, J. H. W. \& J. W. S. col. (MNRJ); Pará: Belém, ㅇ, 2.VII.1922, J. H. Williamson \& J. W. Strehm col. (MNRJ); Óbidos, O', 20.VIII.1962 (MNRJ); Porto Trombetas, O', 21.VI.1982, A. Machado col. (ABMM);

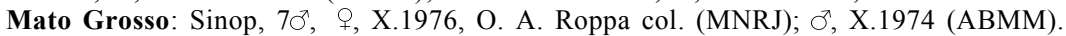

Distribuição geográfica. Brasil (Amazonas, Rondônia, Pará, Mato Grosso) e Guiana Francesa (Caiena). Amplia-se a distribuição para o centro-oeste do Brasil (Mato Grosso).

\section{DISCUSSÃO}

Ris (1911) descreveu Argyrothemis argentea, considerando: 1) metade basal da fronte, base do vértex, dorso do tórax e espaço interalar azul-metálicos; 2) dorso do abdômen com mancha amarela na metade anterior do segundo segmento, manchas laterais na metade anterior do segmento 3 a 5 e uma anterior, não interrompida pela carena dorsal, no segmento $7 ; 3$ ) apêndices superiores divergentes na base, fortemente arqueados, mais curtos que os segmentos $9+10 ; 4)$ apêndices superiores com pequeno dente no ângulo inferior próximo ao ápice; 5) apêndice inferior aproximadamente do mesmo comprimento do superior; 6) hâmulo desenvolvido, robusto, ligeiramente ondulado e inclinado para trás em um ângulo de $45^{\circ}$; 7) lâmina anterior reduzida; 8) lobo genital longo, estreito e pontiagudo, inclinado para trás; 9) asas hialinas, com extremidade distal ligeiramente castanha.

Machos do Brasil, quando comparados com o da Guiana Francesa, apresentam diferenças que nos levaram a considerá-los, inicialmente, como outra espécie: 1) tamanho da mancha da extremidade distal das asas; 2 ) sexto segmento do abdômen com mácula amarela e 3) apêndices superiores com quatro dentes. A presença de único dente foi observado em dois exemplares brasileiros. A mácula castanho-clara na extremidade distal da asa, ocupando toda a área do pterostigma a partir das três últimas pós-nodais, foi observada no espécime de Porto Velho e em sete de Manaus; em um dessa localidade a asa apresenta-se inteiramente hialina. Todos os machos do Mato Grosso apresentam, também, asas inteiramente hialinas. A ausência de mancha no sexto segmento do abdômen, citada por Ris (1911), foi observada em todos os exemplares exceto em um macho do Mato Grosso.

De Marmels (1988), examinou nove machos da Venezuela e quatro do Brasil. Verificou que os exemplares da Venezuela têm asas inteiramente hialinas ou ligeiramente sombreadas, com a maioria da fileira de células da extremidade distal da asa castanhoclara; todos os exemplares do Brasil têm a extremidade de suas asas castanha depois da última pós-nodal. Os exemplares do Brasil apresentam as seguintes variações: o macho de Porto Velho (Rondônia) tem a extremidade distal de suas asas castanha desde a penúltima pós-nodal; sete machos de Manaus (Amazonas) têm a extremidade distal de suas asas semelhante aos do Brasil, examinados por De Marmels; em sete machos do Mato Grosso as asas são inteiramente hialinas semelhantes as do holótipo e aos da Venezuela. Nos machos do Brasil, as asas posteriores medem 21 a $24 \mathrm{~mm}$ e o abdômen 18 a $19 \mathrm{~mm}$; no da Guiana Francesa as asas posteriores medem $23 \mathrm{~mm}$ e o abdômen $19 \mathrm{~mm}$, como no holótipo. Os exemplares do Brasil têm a base dos fêmures amarelas e tíbias pretas. Segundo DE MARMELs (1988), Ris (1911) possivelmente errou ao mencionar somente um dente ventral 


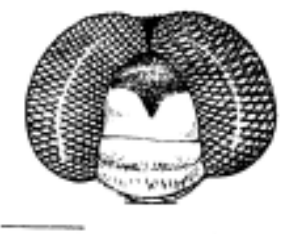

10

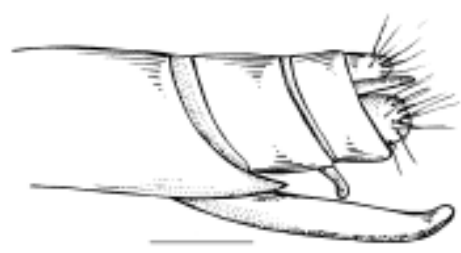

13
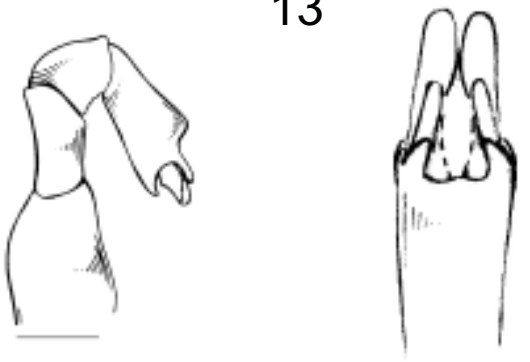

15

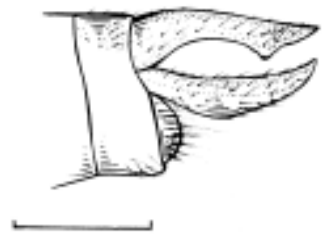

18
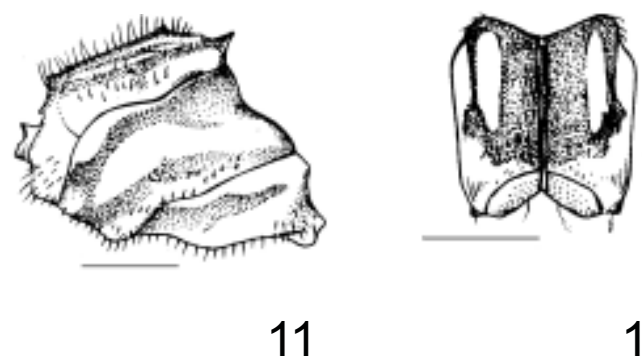

12
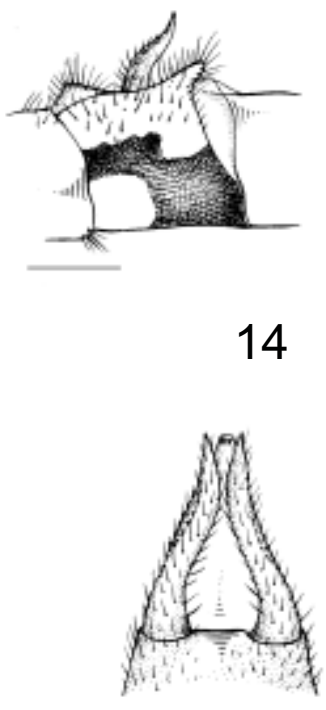

16

17

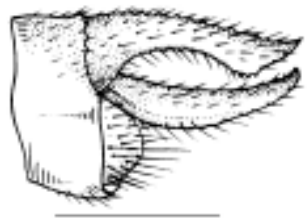

19

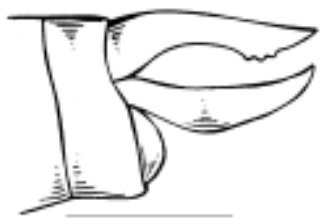

Figs. 10-20. Argyrothemis argentea Ris, 1911. Fêmea (Mato Grosso, Sinop): 10, cabeça, vista dorsal; 11, pterotórax, lateral; 12, pterotórax, dorsal; 13, apêndices superiores, lateral. Macho (Mato Grosso, Sinop): 14, hâmulo, lateral; pênis: 15, lateral; 16, ventral; 17, apêndices superiores, dorsal; apêndice superior lateral: 18, com 1 dente; 19, com 3 dentes; 20, com 4 dentes. Escalas: $2 \mathrm{~mm}$, fig. 10; 5 mm, figs. 11,$12 ; 1 \mathrm{~mm}$, figs. $13,14,17-20 ; 0,5 \mathrm{~mm}$, figs. 15,16 . 
subapical nos apêndices anais superiores do holótipo pois, nos exemplares do Brasil e da Venezuela por ele examinados, os apêndices apresentavam três a quatro dentes. Os do Brasil aqui examinados têm 1 a 4 dentes. Discordamos de De Marmels quanto ao possível erro de Ris, em razão do macho da Guiana Francesa e dois machos do Brasil possuírem único dente. Em um macho do Mato Grosso, o apêndice superior direito apresenta dois dentes e o esquerdo quatro. Os exemplares do Brasil possuem variações estruturais (número de dentes) e de coloração, porém não as consideramos consistentes para definir esses exemplares como pertencentes a um novo táxon, tornando-se necessário examinar material de outras regiões do Brasil.

O pênis dos exemplares examinados (Brasil: Porto Velho, Manaus e Mato Grosso) e o da Guiana Francesa, em vista ventral, é semelhante ao do espécime de Porto Velho, ilustrado por DE MARMELS (1988).

Ris (1911) considerou Argyrothemis relacionado a Uracis, porém referiu que a posição mais correta seria considerá-lo junto aos gêneros que se assemelham a Fylgia Kirby, 1889 com base na nervação da asa anterior. Os dois gêneros possuem apenas uma fileira de células no campo discoidal da asa anterior. Ris (1911) sugeriu que o conhecimento da fêmea de Argyrothemis seria muito desejável para um juízo definitivo sobre a sua posição taxonômica no sistema, o que está sendo realizado agora.

O exame de quatro fêmeas, procedentes do Amazonas, Pará e Mato Grosso, sugere que Argyrothemis possa ser mais intimamente relacionado com Uracis que com qualquer outro gểnero, com base na presença de um ovipositor alongado, muito semelhante ao de Uracis. Outros caracteres compartilhados com Uracis são observados tanto nos machos como nas fêmeas: 1) asa posterior com duas nervuras transversais cúbito-anais; 2) nervura cubital, na asa posterior, amplamente afastada do ângulo anal do triângulo; 3) setores do árculo pedunculados; 4) asas hialinas ou com extremidade distal castanha. Os únicos caracteres compartilhados com Fylgia são a fileira de células no campo discoidal e o triângulo da asa anterior com lado costal quebrado.

Agradecimentos. Ao Dr. Angelo Barbosa Monteiro Machado (Universidade Federal de Minas Gerais) pelo empréstimo de material; ao Prof. John Becker (MNRJ), pela tradução do texto em alemão; ao Dr. Phillipe Machet, Saint-Cloud, França, pela doação do exemplar da Guiana Francesa; à Prof $^{\mathrm{a}}$. Angélica do Nascimento Lourenço (MNRJ), pelas críticas e sugestões. Ao CNPq e FAPERJ, pelos auxílios concedidos. Ao Sr. Luiz Antônio Alves Costa (MNRJ), pelas ilustrações e ao Sr. Roosevelt Rodrigues Mota pelas fotos coloridas.

\section{REFERÊNCIAS BIBLIOGRÁFICAS}

BRIDGES, C. A. 1994. Catalogue of the family-group, genus-group and species-group names of the Odonata of the world. Urbana, C.A. Bridges. 905p.

De Marmels, J. 1988. Odonata or dragonflies from Cerro de la Neblina. Acad. Cienc. Fis. Mat. Naturales, Caracas, 25:1-78.

Rambur, P. 1842. Histoire Naturelle des insects Néuroptères. Paris, Librarie Encyclopédique de Roret. v. 17, 534p.

Ris, F. 1911. Libellulinen. monographisch bearbeited. Collns Zool. Edm. Selys Longschamps, Bruxelles, 12:385-528.

. 1916. Libellulinen monographisch bearbeited. Collns Zool. Edm. Selys Longschamps, Bruxelles, 16:965-1042.

Steinmann, H. 1997. World catalogue of Odonata, Anisoptera. Berlin, W. Gruyter. v. 2, 636p.

Recebido em 26.09.2002; aceito em 02.04.2003. 